\title{
Practices and Services for Enabling the Independent Living of Elderly Population
}

\author{
Apostolos Vontas ${ }^{1}$, Nikolaos Protogeros ${ }^{2}$, and Vasiliki Moumtzi ${ }^{3}$ \\ ${ }^{1}$ ALTEC Research Division, 6 M. Kalou Str., 54629 Thessaloniki, Greece \\ avo@altec.gr \\ ${ }^{2}$ Department of Accounting and Finance, University of Macedonia, 156 Egnatia Str., \\ 54006 Thessaloniki, Greece \\ proto@uom.gr \\ ${ }^{3}$ Faculty of Computing, Information Systems \& Mathematics, \\ Kingston University, London UK \\ vasmoumtzi@gmail.com
}

\begin{abstract}
This paper presents the outcome of the evaluation of existing practices and services that assist the independent living of elderly population. In the context of this investigation we examined already existing practices and services and promote the ones that have the greatest impact to their lives and potential for wider commercial exploitation.
\end{abstract}

Keywords: Assisting living, elderly people, needs, e-services.

\section{Introduction}

Today, there are more than 70 million people aged 60 and over in the EU, representing just under one in five of the population. The category occupied by the very old, the over-eighties, are more likely to become ill and dependant. This category is growing rapidly.

The ageing population creates a market on its own, where a significant amount of online services are created and provided for them. Online services should consider the special needs of ageing people and thus create designs that will include them in the benefits of the Information Society. This requires thinking beyond the conventional media and creating a better overall experience which can be communicated via TV.

Many old people need support, as a consequence of losing mobility, mainly caused by illness. Physical, as well as, mental routines are getting more difficult which is influencing their whole lives. Society acknowledges these problems and seeks for solutions to meet its responsibility. Although institutions as well as medical facilities are available to them, from now on there will be many efforts helping people to stay at home longer. Technological solutions seem to be the way out of the expanding costs of health, help and support (Fuchsberger,2008).

This paper explores the types of online services that empower the independent living of ageing people and the telecommunication technologies that support online services.

During our investigation, we carried out an analysis on already existing software applications that support online services for elderly people. From the above we understand 
that there is an increasingly demand for online homecare services such as emergency treatment, autonomy enhancement and comfort (Nehmer,2006). Meanwhile, telecommunication technology and computer science rapid development established internet use through TV via different communication channels like IP TV and devices such as audiovisual and entertainment equipment, health care devices, home automation systems (Vergados,2008). To this end, our research aims to customise and test a platform integrated according to a user-centric approach for co-creative design and validation of IT products and services set to enhance assisting living of elderly people. Our first intention was to investigate the existing practice and services based on characteristics for interface which could help a platform to reach large audiences more quickly.

\section{Methodology}

Methodology Steps. The steps we followed in our research can be summarized as follows:

(i) We oriented the research to services that empower the independent living of ageing people.

(ii) We focused our research solely on already existing software applications that provide online services for people who live independently and for elderly people.

(iii) We considered relevant information and telecommunication technology approaches and trends that are accessible and acceptable by elderly people.

(iv) We investigated the final user's needs and we proposed the best practices that empower the independent living of ageing people.

(v) We validated the proposed online services through a pilot carried out on real users in Greece.

(vi) We collected the feedback from the final users of the above trial. The kind of feedback given was oriented to human independence living factors. Based on these, a deep analysis on the feedback specified the added value of the services in terms of a user interface that improves the quality of life for elderly people.

Inclusion Criteria. There has been a rapid growth worldwide in mobile telephony, and broadband access has been growing quickly. Digital TV, HDTV, IPTV and mobile TV are all spreading. Nonetheless, there are access problems, especially in emerging countries. There are three main risks to inclusion: availability, accessibility - both in terms of people with disabilities and those lacking in ICT skills - and affordability.

In particular, here are the critical "success factor" keys considered in EICTA ICT "White Paper of Inclusion" [EICTA,2006] as the main risks exclusion:

- Availability: People disadvantaged due to lack of geographical coverage

- Affordability: People do not have access due to a lack of resources. Either the average income of a potential consumer is too low or it is not profitable to provide service due to actual operating costs.

- Accessibility: This has two elements: 1) people with disabilities such as visual, audio, speech, cognitive or mobility related 2) people who are lacking in ICT skills. 


\section{Technology Description}

This research on already existing practices was completed under specific criteria in order to highlight those that facilitate assisting the life of ageing people that cover the following information and telecommunication technology approaches.

Table 1. List of projects investigated on e-services for aging people

\begin{tabular}{|c|c|c|}
\hline & Advantages & Disadvantages \\
\hline $\begin{array}{l}\text { OLDES - 045282 - } \\
\text { (Older People's e- } \\
\text { services at home) }\end{array}$ & $\begin{array}{l}\text { - User entertainment services, through easy-to- } \\
\text { access thematic channels } \\
\text { - Special interest forums supported by animators } \\
\text { - Health care facilities based on established } \\
\text { Internet and tele-care communication standards. }\end{array}$ & $\begin{array}{l}\text { The aren't any e- } \\
\text { services for other } \\
\text { fields(such as } \\
\text { social services) }\end{array}$ \\
\hline $\begin{array}{l}\text { SOPRANO - 045212 - } \\
\text { (Service Oriented } \\
\text { PRogrammable smArt } \\
\text { nviroNments for Older } \\
\text { Europeans) }\end{array}$ & $\begin{array}{l}\text { - Older people at affordable cost } \\
\text { - Meeting requirements of users, family and care } \\
\text { providers } \\
\text { - Significantly extending the time we can live } \\
\text { independently at homes when older. }\end{array}$ & $\begin{array}{l}\text { There is not a } \\
\text { deep analysis of } \\
\text { the devices which } \\
\text { users and family } \\
\text { will use }\end{array}$ \\
\hline $\begin{array}{l}\text { SHARE-it- } 045088 \text { - } \\
\text { (Supported Human } \\
\text { Autonomy for Recovery } \\
\text { and Enhancement of } \\
\text { cognitive and motor } \\
\text { abilities using IT) }\end{array}$ & $\begin{array}{l}\text { - } \text { Sensor networks } \\
\text { - Assisted mobility } \\
\text { - } \text { Knowledge engineering } \\
\text { - Ambient Intelligence }\end{array}$ & $\begin{array}{l}\text { E-services selec- } \\
\text { tion is not a part } \\
\text { of this research }\end{array}$ \\
\hline $\begin{array}{l}\text { PERSONA - } 045459 \text { - } \\
\text { (PERceptive Spaces } \\
\text { prOmoting iNdependent } \\
\text { Aging) }\end{array}$ & $\begin{array}{l}\text { - AAL system reference architecture } \\
\text { - Micro- and nano-electronics } \\
\text { - Human Machine Interfaces } \\
\text { - } \text { Communication } \\
\text { - Software, web and network technologies } \\
\text { - Biosensors, embedded and distributed sensors } \\
\text { - Energy generation and control technologies } \\
\text { - Intelligent software. Tools for decision support. }\end{array}$ & $\begin{array}{l}\text { The project } \\
\text { doesn't include a } \\
\text { research about the } \\
\text { e-services that } \\
\text { facilitate assisting } \\
\text { living. The re- } \\
\text { search is mainly } \\
\text { technical oriented }\end{array}$ \\
\hline $\begin{array}{l}\text { VITAL (Vital } \\
\text { Assistance for the } \\
\text { Elderly) }\end{array}$ & $\begin{array}{l}\text { - inter-personal communication, } \\
\text { - personal advice, } \\
\text { - entertainment, } \\
\text { - Ability to move safely in the physical } \\
\text { environment }\end{array}$ & $\begin{array}{l}\text { The project is } \\
\text { centered only to } \\
\text { mobile devices }\end{array}$ \\
\hline $\begin{array}{l}\text { T-Seniority- 224988- } \\
\text { (Expanding the benefits } \\
\text { of Information Society to } \\
\text { Older People } \\
\text { through digital TV) }\end{array}$ & $\begin{array}{l}\text { T-Seniority covers: } \\
\bullet \text { a diverse range of care needs in a wide range of } \\
\text { service situations (home care, tele-assistance, } \\
\text { mobile telecom services). } \\
\bullet \text { This innovative service provision will use digital } \\
\text { TV. }\end{array}$ & $\begin{array}{l}\text { The selected } \\
\text { implemented e- } \\
\text { services are not } \\
\text { analyzed in details }\end{array}$ \\
\hline $\begin{array}{l}\text { MonAMI - 035147 - } \\
\text { (Mainstreaming on } \\
\text { Ambient Intelligence) }\end{array}$ & $\begin{array}{l}\text { - Comfort applications: home control, } \\
\text { personalised communication interface, activity } \\
\text { planning } \\
\text { - Health: monitoring, medication } \\
\text { - Safety and security: safety at home, visitor } \\
\text { validation, activity detection }\end{array}$ & $\begin{array}{l}\text { There is not a } \\
\text { deep analysis } \\
\text { regarding the } \\
\text { devices which } \\
\text { users will finally } \\
\text { use }\end{array}$ \\
\hline
\end{tabular}


Online Services. Many elderly people need support, due to a deterioration of mobility, often caused by illness. This is not only observed in their physical state but also their mental, thus influencing their whole lives. Society acknowledges this and seeks efficient ways of support in order to meet its responsibility. Although institutions and medical facilities are available to them, from now on there will be many efforts helping people to stay at home longer. Technological solutions seem to be the way out of the expanding costs of health, help and support.

The presented case study implements the above kind of services using the following technologies:

\section{Services for public interest:}

- Massive broadcast and access to general interest information, being supplied by public administrations or general content providers (meteorological info, public administrations campaigns and advices, public e-Care Services resources availability, etc.)

- A public e-Care Services repository with extensive information on facilities, persons and programmes / resources dealing with Social Care services provision.

- An appointment module with e-Care Services Public Providers.

- A reservation module for reserving or contracting the use of public e-Care Services resources in a concrete timeframe.

- A "Talk with your PA" module to create direct and always-on communication channels among e-Care Services users and its public administration supervisors.

- A procedure management module to access, start and even accept (using digital signatures, certificates and biometric parameters) the enrolment in available public e-Care Services.

\section{Personalized services:}

- An elder communication module to be permanently in contact with their environment by using from simple call backs (low interactivity) to Voice and Video over Internet protocol (V\&VoIP) (high interactivity) technologies, including audio and video conference services from home with family, friends, carers and people of the Local Council, according to each user needs.

- A module for Requesting Services for an Independent Living, from which the elder (under the accreditation and control of the Administration), using only a TV remote control, is able to request public or personalized services and to select the providers that will serve him, in matters as diverse as: primary care, pharmacies, transport, meals delivery, teleshopping, entertainment, etc. The Elder-Provider easy of use was the key for success for the rollout of the services and the first TSeniority users have confirmed this assumption. (Medium interactivity).

- A Tele-monitoring Independent Living module (high interactivity), for controlling conditions about:

○ Emergencies: existent tele-assistance systems, personalized alerts, fall detection, inactivity detection, etc.

○ Living Environment: temperature, humidity, gas presence, fire and flood detections, etc.

○ Vital parameters: blood pressure, sugar level, weight body, etc. 
Telecommunication Technologies. Today, end users sitting in front of the TV screen, with a remote control in hand, will be able to choose among many different options of public or personalized services: communicate with their relatives, friends and colleagues; ask for shopping, repairs, appointments, on-line banking, etc... Typical TV end-users will not need to worry about what kind of technology is behind their personal services at home (STB (Set Top Box) adapted to DTT-MHP, IPTV, IPHOMENETWORKING (IPHN), etc., or their interoperability, because these are completely hidden from them. The users have immediate and easy access to everything they can do, for example, talking with their children by just focusing on a photo with the remote TV control and pressing OK, simply using the remote TV control they already know how to manage. They do not need to go through a difficult learning curve. The telecommunication technologies should facilitate the following:

- Services on Mobiles Devices: The internet, computers, even mobile phones, are terms and tools that the elderly are not used to. It is not easy for them to use these and in most cases they create psychological barriers for the access and use of healthcare services.

- Services in Public Kiosks: This kind of terminals (as desktop models, cashier like or adapted for people with disabilities), which are located inside or outside strategic points where people usually gather.

- Services on TV: The TV channel can be an effective mean to include communities of users to the world of interactive services.

\section{Expected Results}

For special group of users who are typically not familiar with technologies the assistive environments are considered unique.

The likely benefits might include:

- Better quality of e-services that facilitate independent living of aging people tested, and perhaps an easier and more extended development of innovations in the European market.

- Improve quality of life of older people and their families and increase effectiveness of care systems, and facilitate wide implementation by the public authorities innovative, chronic disease management services.

- More tangible benefits to the underlying local communities of stakeholders and citizens.

\section{Conclusions}

It is obvious to us that there is a high need for substantially prolonging the time that elderly people can live independently at home and manage their day-today activities in a socially integrated manner. In case someone needs help for independent living which e-services are available to use? Taking in mind that he doesn't have high IT skills how he will be trained to access the internet and through which telecommunication channel? Our experiences show that the concept of online services, which can be 
easily operated by the elderly, can be an extremely beneficial tool for facilitating living. Any sustainable adoption and usage of online services would need a careful requirements analysis in order to determine the form and extent of elderly population needs. With this in mind, the research emphasizes on the technologies and online services which can easily be operated by elderly and disabled people. Providers, suppliers and designers of e-service tools and methods should examine every aspect of elderly peoples' needs as well as the suitability of the technologies before providing access to the tools. By doing this, the future e-service tools will serve a specific function in a specific situation and therefore provide maximum benefit to a particular group of users and developers (rather than random benefits to diffuse and undefined stakeholders).

The authors' experience and evidence from the results of this research have led to believe that situation-specific online services platforms would be greatly beneficial in providing the elderly a universal access to service resources.

\section{References}

1. Fuchsberger, M. V.: Ambient assisted living: elderly people's needs and how to face them. In: Proceeding of the 1st ACM international workshop on Semantic ambient media experiences, SAME 2008 (October 2008)

2. Nehmer, J., Becker, M., Karshmer, A., Lamm, R.: Living assistance systems: an ambient intelligence approach. In: Proceedings of the 28th international conference on Software engineering, ICSE 2006 (May 2006)

3. Vergados, D., Alevizos, A., Mariolis, A., Caragiozidis, M.: Intelligent Services for Assisting Independent Living of Elderly People at Home. In: Proceedings of the 1st international conference on PErvasive Technologies Related to Assistive Environments, PETRA 2008 (July 2008)

4. OLDES - 045282 - (Older People's e-services at home)

5. SOPRANO - 045212 - (Service Oriented PRogrammable smArt enviroNments for Older Europeans)

6. SHARE-it- 045088 - (Supported Human Autonomy for Recovery and Enhancement of cognitive and motor abilities using information technologies)

7. ST-2005-2.6.2 Ambient Assisted Living (AAL) in the Ageing Society European Commission, IST 045459

8. VITAL (Vital Assistance for the Elderly) Contract Type: Specific Targeted Research Project

9. MonAMI - 035147 - (Mainstreaming on Ambient Intelligence)

10. EICTA: European Information \& Communications Technology Industry Association. i2010: Toward an Inclusive Information Society. ICT industry White Paper on inclusion, Brussels (December 2006) 